\title{
Elevated Serum Antibody Levels against Cyclin L2 in Patients with Esophageal Squamous Cell Carcinoma
}

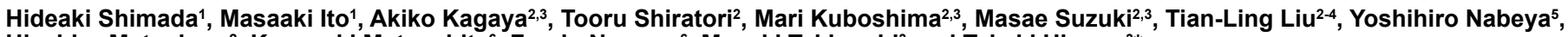
Hisahiro Matsubara ${ }^{2}$, Kazuyuki Matsushita $^{6}$, Fumio Nomura $^{6}$, Masaki Takiguchi ${ }^{3}$ and Takaki Hiwasa $^{3 *}$

${ }^{1}$ Department of Surgery, Graduate School of Medicine, Toho University, Ota-ku, Tokyo 143-8541, Japan

${ }^{2}$ Department of Frontier Surgery, Graduate School of Medicine, Chiba University, Chuo-ku, Chiba 260-8670, Japan

${ }^{3}$ Department of Biochemistry and Genetics, Graduate School of Medicine, Chiba University, Chuo-ku, Chiba 260-8670, Japan

${ }^{4}$ Health Management Department, Aerospace Center Hospital, Beijing 100049, China

${ }^{5}$ Division of Gastroenterological Surgery, Chiba Cancer Center, Chuo-ku, Chiba 260-8717, Japan

${ }^{6}$ Department of Molecular Diagnosis, Graduate School of Medicine, Chiba University, Chuo-ku, Chiba 260-8670, Japan

\begin{abstract}
Cyclin L2 (CCNL2) (Acc. No.: NM_030937) was detected as a tumor antigen of esophageal squamous cell carcinoma (SCC) by serological identification of antigens by recombinant cDNA expression cloning (SEREX). Serum anti-CCNL2 antibodies were detected by enzyme-linked immunosorbent assay more frequent in patients with esophageal SCC than in healthy donors $(32 \%$ and $15 \%, \mathrm{P}<0.01)$. An AlphaLISA further confirmed the significant difference in serum antibody levels between the patients and healthy donors using a different set of serum specimens. The expression levels of CCNL2 mRNA detected by reverse transcription polymerase chain reaction were higher in esophageal SCC tissues than those detected in adjacent normal esophageal tissues. We then analyzed for biological function by the transient transfection of CCNL2 expression plasmids into ras-NIH3T3 mouse fibroblasts followed by analysis via luciferase assay using p53-responsive reporter plasmids. CCNL2 increased the transactivation ability of $p 53$, which was attenuated by protein kinase $C$ (PKC) inhibitors or a dominant negative PKCa. Thus, it is possible that CCNL2 activates p53 via PKC $\alpha$ activation.
\end{abstract}

Keywords: Esophageal squamous cell carcinoma; SEREX; Cyclin L2; p53

Abbreviations: AlphaLISA: Amplified Luminescence Proximity Homogeneous Assay; CCNL2: Cyclin L2; DMEM: Dulbecco's Modifield Eagle's Medium; DMSO: Dimethyl Sulfoxide, DN: Dominant Negative; ELISA: Enzyme-linked Immunosorbent Assay; GST: Glutathione-Stransferase; IPTG: Isopropyl $\beta$-D-thiogalactopyranoside; PKC: Protein Kinase C; SCC: Squamous Cell Carcinoma; s-CCNL2-Abs: Serum Anti-CCNL2 Antibodies

\section{Introduction}

Esophageal squamous cell carcinoma (SCC) is a highly malignant disease. Despite improvements of surgical techniques and introduction of multimodal treatments, patients' survival remains poor, particularly in advanced stages [1]. Because such poor prognosis is often due to delayed diagnosis, convenient tools for early diagnosis are indispensable. Serum tumor markers have the potential to be used for early detection. Although conventional serum markers for esophageal SCC, such as SCC antigen, CYFRA21-1 and CEA, cannot detect early stages of tumors [2], the recently developed serum p53 antibodies test is useful for detecting superficial esophageal SCC [2]. Because positive rate of serum p53 antibody is around $30 \%$, another serum antibody is essential to improve the positive rate with a combination assay.

For identifying serum antibody-type tumor markers, serological identification of antigens by recombinant cDNA expression cloning (SEREX) is an effective screening method [3]. SEREX can be used for the immunoscreening of cDNA libraries prepared from tumor specimens with either autologous or allogeneic sera. Furthermore, antigens are easily identified by sequencing the isolated cDNA clones, making SEREX suitable for the large-scale screening of tumor antigens. SEREX has been applied to various human tumor types, and has identified more than 1000 novel tumor antigens [4]. We have previously performed large scale SEREX screening and identified new tumor antigens of esophageal SCC [5-11]. It has been suggested that most, if not all, of the esophageal SEREX antigens are related to carcinogenesis, apoptosis or cell growth [8-10]. For example, the tumor suppressor $\mathrm{p} 53$, the oncoprotein phosphatidylinositol 3-kinase and stathmin have been identified by our SEREX screening method. Therefore, the analysis of the function of other SEREX clones may yield intriguing results.

Here we identified cyclin L2 (CCNL2) as a novel SEREX antigen of esophageal SCC and observed that the levels of serum anti-CCNL2 antibodies (s-CCNL2-Abs) are higher in patients with esophageal SCC than those in patients with stomach or colon cancer and much higher than those in healthy donors. Possible activation of PKCa by CCNL2 is discussed.

\section{Materials and Methods}

\section{Drugs}

Geldanamycin, GF109203X (PKC inhibitor), 3-ATA (CDK4 inhibitor), parthenolide (NF-kB inhibitor) and Akt inhibitor were purchased from Alexis (Lausen, Switzerland). SP600125 (JNK

*Corresponding author: Takaki Hiwasa, Department of Biochemistry and Genetics, Graduate School of Medicine, Chiba University, Inohana 1-8-1, Chuoku, Chiba 260-8670, Japan, Tel: +81-43-226-2541; Fax: +81-43-26-2037; E-mail: hiwasa_takaki@faculty.chiba-u.jp

Received December 22, 2014; Accepted February 23, 2015; Published February 25, 2015

Citation: Shimada H, Ito M, Kagaya A, Shiratori T, Kuboshima M, et al. (2015) Elevated Serum Antibody Levels against Cyclin L2 in Patients with Esophageal Squamous Cell Carcinoma. J Cancer Sci Ther 7: 060-066. doi:10.4172/1948 5956.1000326

Copyright: @ 2015 Shimada $\mathrm{H}$, et al. This is an open-access article distributed under the terms of the Creative Commons Attribution License, which permits unrestricted use, distribution, and reproduction in any medium, provided the original author and source are credited. 
inhibitor), p38 MAP kinase inhibitor, staurosporine (myosin light chain kinase and PKC inhibitor), K252a (CaM kinase, PKC and PKG inhibitor) and HA14-1 (Bcl-2 inhibitor) were from Merck (Damstadt, Germany). Olomoucine (CDK inhibitor) was obtained from Biomol (Plymouth Meeting, PA). These drugs were dissolved in dimethyl sulfoxide (DMSO) and stored at $-30^{\circ} \mathrm{C}$ until use.

\section{Sera from patients with esophageal SCC}

This work was approved by the Ethic Committee of Chiba University, Graduate School of Medicine. The sera were collected after obtaining the written, informed consent of the patients before treatment for esophageal SCC. Each serum sample was centrifuged at $3,000 \times \mathrm{g}$ for $5 \mathrm{~min}$ and the supernatant was stored at $-80^{\circ} \mathrm{C}$ until use.

\section{Plasmids}

The eukaryotic expression vector pME18S-FL3 containing human CCNL2 cDNA was purchased from Toyobo (Osaka, Japan). pCMV-p53 [12] and reporter plasmids, pG13-Luc [13] and pBVPUMA Frag2-Luc [14], were provided by Dr. Bert Vogelstein (Howard Hughes Medical Institute). The plasmids; pGL3-p21-Luc [15], pGL3Bax-Luc [16] and pGL3-Bad-Luc [17] were provided by Dr. Mian Wu (University of Science and Technology of China). pGV-B2 Noxa-Luc [18] was provided by Dr. Nobuyuki Tanaka (Nippon Medical School). Control reporter SV40-Rluc was purchased from Promega (Madison, WI). Dominant negative PKCa and PKCE $\varepsilon$ (PKCa-DN and PKCE $\varepsilon$ DN) were provided by Dr. Shigeo Ohno (Yokohama City University School of Medicine) [19]. Dominant negative JNK (JNK-DN) was provided by Dr. Eisuke Nishida (Kyoto University).

\section{SEREX screening}

A $\lambda$ ZAP II phage cDNA library was prepared from the mRNA of the T.Tn cells $[20,21]$, and the immunological screening was performed as described previously [5-11]. The monoclonalized phage cDNA clones were converted to pBluescript phagemids by in vivo excision using ExAssist helper phage (Stratagene, La Jolla, CA). This phagemid was then used to acquire plasmid DNA from the E. coli strain SOLR.

\section{Western blot analysis}

The presence of serum antibodies to the CCNL2 protein was examined by Western blot analysis. E. coli JM109 cells, which contained CCNL2 cDNA clone recombined in pBluescript II, were cultured with or without $0.1 \mathrm{mM}$ isopropyl $\beta$-D-thiogalactopyranoside (IPTG) for 2.5 h. After which, the cells were washed with PBS and then lyzed by being incubated in a sodium dodecyl sulfate (SDS) sample buffer at $100^{\circ} \mathrm{C}$ for $3 \mathrm{~min}$. The E. coli lysate was then subjected to SDS-polyacrylamide gel electrophoresis, followed by Western blotting using the sera of patients as described $[5,7,8]$.

\section{Purification of recombinant proteins}

cDNA insert of CCNL2 cDNA incorporated in pBluescript II was cleaved by EcoRI and XhoI, and recombined in pGEX-4T (GE Healthcare). E. coli JM109 cells containing either pGEX-4T-3CCNL2 or the control, pGEX-4T-3, were cultured in $200 \mathrm{ml}$ of Luria broth (LB) and then treated with $0.1 \mathrm{mM}$ IPTG for $2.5 \mathrm{~h}$. The cells were then harvested, washed with PBS and lysed by sonication in Bugbuster extraction reagent (Merck). The lysate was then centrifuged at $10,000 \times \mathrm{g}$ for $30 \mathrm{~min}$ at $4^{\circ} \mathrm{C}$. The glutathione-S-transferase (GST)fusion proteins found in the supernatant were affinity-purified by glutathione-Sepharose (GE Healthcare) and then concentrated using Apollo centrifugal concentrators (Orbital Biosciences, Topsfield, MA).

\section{Enzyme-linked immunosorbent assay (ELISA)}

A total of 72 patients were analyzed by ELISA. Fifty $\mu$ l of antigens (GST or GST-CCNL2) diluted to $10 \mu$ g protein/ml in PBS were added to the wells of a microtiter plate, and then incubated at room temperature overnight. The plate was washed 4 times with $0.1 \%$ Tween-20 in PBS (PBS-T) and then blocked with $10 \%$ fetal bovine serum in PBS (PBSFBS). The plate was incubated at room temperature for $1 \mathrm{~h}$ and washed 4 times with PBS-T. Fifty $\mu$ of the respective sera, diluted to $1 / 100$ in PBS-FBS, were added to the wells and incubated for $1 \mathrm{~h}$. The wells were washed with PBS-T 4 times, and the bound IgG antibodies were detected by incubation with horseradish peroxidase-conjugated antihuman IgG antibody (Jackson Immuno Research Laboratories, West Grove, PA) for $1 \mathrm{~h}$, followed by washing and the addition of $100 \mu \mathrm{l}$ of a peroxidase substrate ( $o$-phenylenediamine, $0.4 \mathrm{mg} / \mathrm{ml}$ ) in citratephosphate buffer, $(\mathrm{pH} 5.0)$ containing $0.02 \%(\mathrm{v} / \mathrm{v}) \mathrm{H}_{2} \mathrm{O}_{2}$. The reaction was stopped with $30 \mu \mathrm{l}$ of $22 \% \mathrm{H}_{2} \mathrm{SO}_{4}$. The absorbance at $490 \mathrm{~nm}$ was determined with a microplate reader (Emax, Molecular Devices, Sunnyvale, CA) as described $[5,7,8]$.

\section{AlphaLISA}

The AlphaLISA (Amplified Luminescence Proximity Homogeneous Assay) method was used to evaluate the serum antibody levels. The serum specimens used were taken from 80 healthy donors, 80 patients with gastric cancer, 92 patients with colon carcinoma and 80 patients with esophageal carcinoma. The AlphaLISA was performed in 384well microtiter plates (white opaque OptiPlate ${ }^{\mathrm{mm}}$ from Perkin Elmer, Waltham, MA) containing $2.5 \mu \mathrm{L}$ of $1 / 100$-diluted serum and $2.5 \mu \mathrm{L}$ of GST-fusion antigen proteins $(10 \mu \mathrm{g} / \mathrm{ml})$ in an AlphaLISA buffer $(25 \mathrm{mM}$ HEPES, $\mathrm{pH} 7.4,0.1 \%$ casein, $0.5 \%$ Triton X-100, $1 \mathrm{mg} / \mathrm{mL}$ dextran- 500 , and $0.05 \%$ Proclin-300). The reaction mixture was incubated at room temperature for $6 \mathrm{~h}$, then anti-human IgG-conjugated acceptor beads $(2.5 \mu \mathrm{L}$ at $40 \mu \mathrm{g} / \mathrm{mL})$ and glutathione-conjugated donor beads $(2.5 \mu \mathrm{L}$ at $40 \mu \mathrm{g} / \mathrm{mL}$ ) were added and incubated at room temperature in the dark for another 1 - 7 days. The plate was read on an EnSpire Alpha microplate reader (PerkinElmer).

\section{Reverse transcription-PCR (RT-PCR)}

Total cellular RNA was isolated from cultured cells using the AquaPure RNA Isolation kit (Bio-Rad, Hercules, CA). Reverse transcription was performed with an oligo $(\mathrm{dT})_{20}$ primer using the ThermoScript RT-PCR System (Thermo Fisher Scientific, Waltham, MA). PCR amplification using the following primers;

\section{CCNL2 sense: 5'-CTGTCCCATTTCAACAAGGGG-3' \\ CCNL2 antisense: 5'-CAAGATAGAAGAGGCCCCAAG-3'}

\section{$\beta$-actin sense: 5'-ACCACAGCTGAGAGGGAAATC-3'}

\section{$\beta$-actin antisense: 5'-AGCACTGTGTTGGCATAGAGG-3'}

PCR amplification using the CCNL2 primers was performed using KOD-Plus-DNA polymerase (Toyobo) as follows: an initial denaturation at $94^{\circ} \mathrm{C}$ for $3 \mathrm{~min}$, followed by 30 cycles of denaturation step at $94^{\circ} \mathrm{C}$ for $30 \mathrm{sec}$, annealing at $61^{\circ} \mathrm{C}$ for $30 \mathrm{sec}$, and extension at $68^{\circ} \mathrm{C}$ for $30 \mathrm{sec}$ with a final extension at $68^{\circ} \mathrm{C}$ for $5 \mathrm{~min}$. PCR amplification using the $\beta$-actin primers was conducted as follows: an initial denaturation at $94^{\circ} \mathrm{C}$ for $3 \mathrm{~min}$, followed by 20 cycles of denaturation step at $94^{\circ} \mathrm{C}$ for $30 \mathrm{sec}$, annealing at $60^{\circ} \mathrm{C}$ for $30 \mathrm{sec}$, and extension at $68^{\circ} \mathrm{C}$ for $30 \mathrm{sec}$ with a final extension at $68^{\circ} \mathrm{C}$ for $5 \mathrm{~min}$ as described $[5,10]$. 


\section{Realtime RT-PCR}

The expression levels of CCNL2 transcripts were quantitated by realtime RT-PCR with the standard of GAPDH using the following primers and probes (Universal Probe Library; Roche, Basel, Switzerland).

\section{CCNL2 sense: 5'-AGCGTAACCAACACCTGGTC-3'}

CCNL2 antisense: 5'-GCAAGATAAATGCAGGCACA-3'

CCNL2 probe: \#20

\section{GAPDH sense: 5'-AGCCACATCGCTCAGACA-3'}

\section{GAPDH antisense: 5'-GCCCAATACGACCAAATCC-3'}

\section{GAPDH probe: \#60}

PCR was performed using Fast Start Taq Man probe Master (Roche) and an ABI PRISM 7000 Sequence Detection System (Applied Biosystems LLC) as follows: an initial denaturation step at $95^{\circ} \mathrm{C}$ for $2 \mathrm{~min}$, followed by 55 cycles of denaturation at $95^{\circ} \mathrm{C}$ for $15 \mathrm{sec}$ and annealing/ extension at $60^{\circ} \mathrm{C}$ for $30 \mathrm{sec}$. The mean and SD for the $-\Delta \Delta \mathrm{CT}$ were calculated and normalized to the GAPDH value as described [11].

\section{Cell culture and luciferase assay}

Mouse ras-NIH3T3 fibroblasts [22] were cultured in Dulbecco's modifield Eagle's medium (DMEM, Sigma-Aldrich) supplemented with $5 \%$ bovine serum (Bio West, Nuaille, France) and $100 \mu \mathrm{g} / \mathrm{ml}$ kanamycin as described [23].

The cells were seeded on 24-well plates and then transfected with CCNL2 expression plasmid or control empty vector plasmid along with firefly luciferase and Renilla luciferase reporter plasmids using LipofectAMINE-Plus (Thermo Fisher Scientific). Two days after the transfection, firefly and Renilla luciferase activities were determined using a Dual Luciferase Assay System (Promega) and a luminescencer (Atto, Tokyo, Japan). Afterwards, the firefly luciferase activities were normalized with the Renilla luciferase control activities as described [24].

\section{Results}

\section{Isolation of CCNL2 cDNA by SEREX}

A reactive clone was isolated from the $1 \times 10^{6} \mathrm{cDNA}$ clones which were screened by SEREX using the sera from esophageal cancer patients. A search for homologous sequence in NCBI-accessible databases (http://www.ncbi.nlm.nih.gov/) revealed that the isolated clone was identical to CCNL2 (cyclin L2) variant 1 (Accession No: NM_030937). The region between nucleotides 701 and 2113 of cDNA was isolated, whereas coding sequence is between 33 and 1595 .

\section{Presence of serum anti-CCNL2 antibodies (s-CCNL2-Abs) in patients with esophageal SCC}

To examine for the presence of s-CCNL2-Abs, Western blotting was performed using allogeneic sera obtained from patients with esophageal SCC. An example is presented in Figure 1. IPTG-pretreatment of the bacteria induced cDNA expression specifically. A positive reaction at $30 \mathrm{kDa}$ was only observed in patients $\mathrm{T} 1$ and T23 when the extract of IPTG-treated CCNL2-cDNA-containing bacteria was probed with serum IgG. The size corresponds to the product of CCNL2 cDNA region isolated by SEREX (297 amino acids).
The levels of s-CCNL2-Abs were examined with ELISA using purified recombinant proteins. The sera from the 42 subjects in each group, healthy donors and patients with esophageal SSC, colon carcinoma and mammary carcinoma, were subjected to ELISA testing to obtain the levels of s-CCNL2-Abs. When the cut-off value was determined as the average $+2 \mathrm{SD}$ of healthy donors, the positive rate of esophageal SCC was approximately $30 \%$, which was higher than that of healthy donors (14\%), and patients with colon (12\%) and mammary carcinoma (16\%). However, these values were not significant possibly due to the large variation in data.

Using AlphaLISA, it is possible to quantitate the precise levels of serum antibodies. Compared with the levels of s-CCNL2-Abs in HD, those of patients with esophageal SCC were much higher although some increase was observed in gastric cancer and colon carcinoma (Figure 2b; details are shown in Supplementary Table S1). The positive rates of esophageal SCC, gastric cancer, colon carcinoma and HD were $16.3 \%$, $10.0 \%, 13.0 \%$ and $2.5 \%$, respectively. Upon further validation testing using another set of 95 specimens of both HD and esophageal SCC, we observed a clear difference between the two groups $(\mathrm{P}=0.000001$; Figure 2c, Supplementary Table S2). No significant correlation was observed between the s-CCNL2-Abs levels and the gender or age of patients by Spearman's correlation analysis.

\section{Expression of CCNL2 in esophageal SCC}

The expression levels of CCNL2 mRNA in esophageal cell lines were examined by RT-PCR analysis. The results revealed that the expression of CCNL2 was hardly observed in normal keratinocytes but was clearly detected in esophageal SCC cell line, T.Tn and immortalized esophageal keratinocytes, EN-60 (Figure 3a). Similar levels were also observed when the commercially available RNA from human esophageal SCC was used as a template. The expression levels of CCNL2 mRNA in esophageal SCC (T) as well as the surrounding normal esophageal tissues $(\mathrm{N})$ were also examined. When compared to the expression levels of normal tissues, most pairs displayed higher expression levels of CCNL2 mRNA in carcinoma tissues. These results

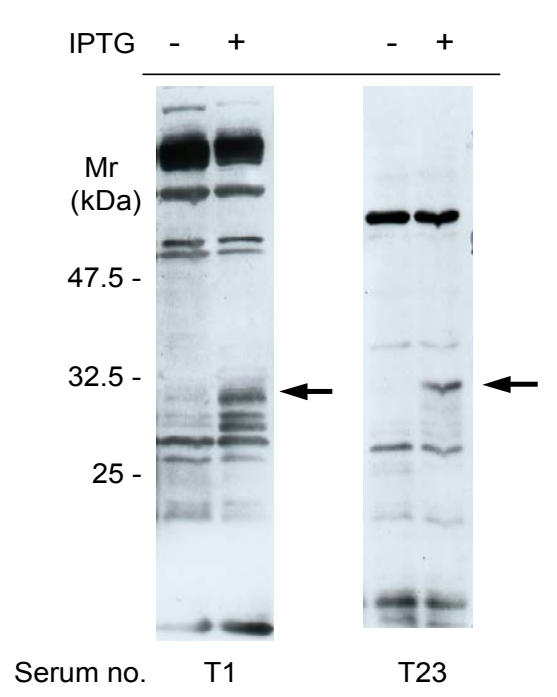

Figure 1: The presence of s-CCNL2-Abs in patients with esophageal SCC. E.coli containing CCNL 2 CDNA plasmid was treated with $(+)$ or without (-) IPTG for $2.5 \mathrm{~h}$, and the total cell lysate was subjected to Western blot analysis using sera of esophageal cancer patient T1 and T23. Arrows indicate the IPTG-dependent specific bands, which represent CCNL2 cDNA products. 
a

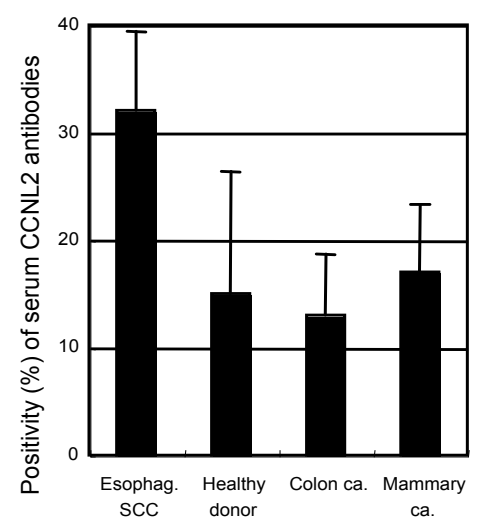

b

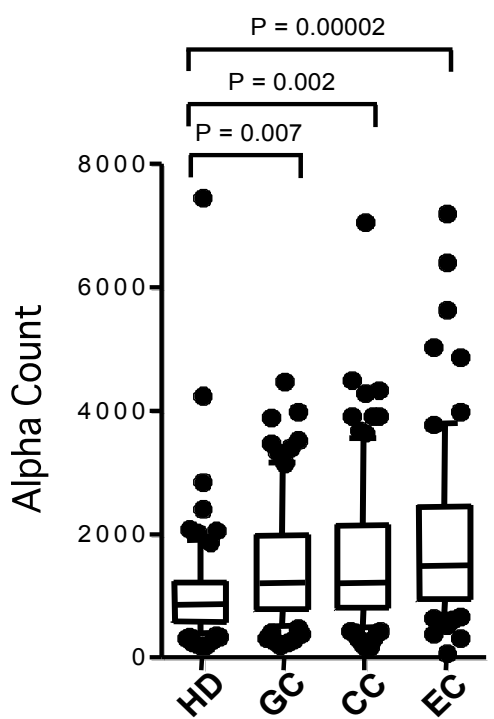

C

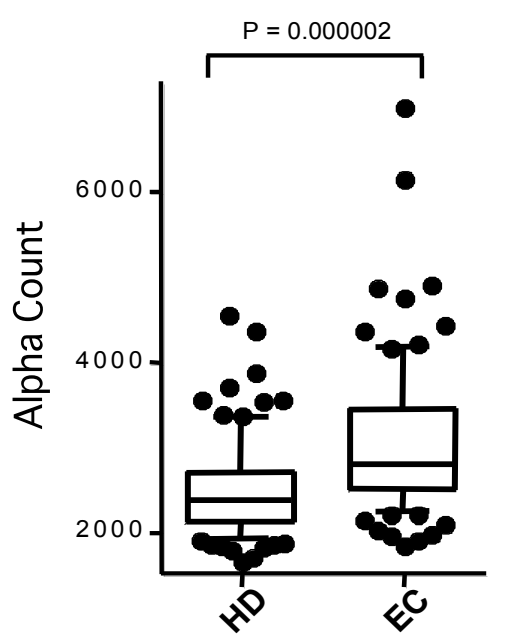

Figure 2: Comparison of levels of s-CCNL2-Abs. a, Shown are the positive rates of s-CCNL2-Abs in the patients with esophageal SCC, healthy donors, and patients with colon carcinoma or mammary carcinoma examined by ELISA. b, The levels of s-CCNL2-Abs in healthy donors (HD), gastric cancer (GC), colon carcinoma (CC) and esophageal SCC (EC) examined by AlphaLISA are shown. P values were calculated by Mann-Whitney $U$ test. c, As a validation test, the s-CCNL2-Abs levels were analyzed by AlphaLISA using another set of sera.

were further confirmed by realtime RT-PCR of 12 pairs of tumor and normal tissues examined, the significant elevation of CCNL2 mRNA was observed in six (Figure 3b).

\section{Functional analysis of CCNL2 by reporter assay}

The activity of p53 is suppressed in most of tumor cells, and its transactivation ability can be examined using luciferase reporters such as p21-Luc Bax-Luc, Bad-Luc, PUMA-Luc and Noxa-Luc. Unexpectedly, pG13-Luc and Bax-Luc were activated by co-transfection with CCNL2 (Figure 4a). The activation was dose-dependent, whereas PUMA-Luc and Noxa-Luc were not activated at all.

We then examined the signaling pathway leading to p53 activation by CCNL2 using various enzyme inhibitors. Activation of pG13-Luc by CCNL2 was inhibited by treatment with staurosporine, olomoucine and K252a, which are inhibitors of protein kinase C (PKC) or cdk (Figure 4b).
The involvement of PKC in the upstream pathway of p53 activation was further examined using dominant negative (DN) mutants, which can specifically suppress the activity of the target protein. The activation of pG13-Luc by CCNL2 was suppressed by co-transfection the cDNA of PKCa-DN but not PKCe-DN or JNK-DN (Figure 4c). Thus, CCNL2 may elevate 553 transcriptional activity via PKCa.

\section{Discussion}

We have identified CCNL2 as a novel marker for esophageal SCC by SEREX screening followed by validation testing. The levels of serum antibodies against CCNL2 (s-CCNL2-Abs) were better indicators of esophageal SCC than those of gastric or colorectal cancer (Figure 2a and b, Supplementary Table S1). Validation tests using another set of serum specimens confirmed a marked and reproducible difference between samples from patients with esophageal SCC and healthy donors (Figure 2c). The levels were higher to a certain degree in patients with gastric 
a
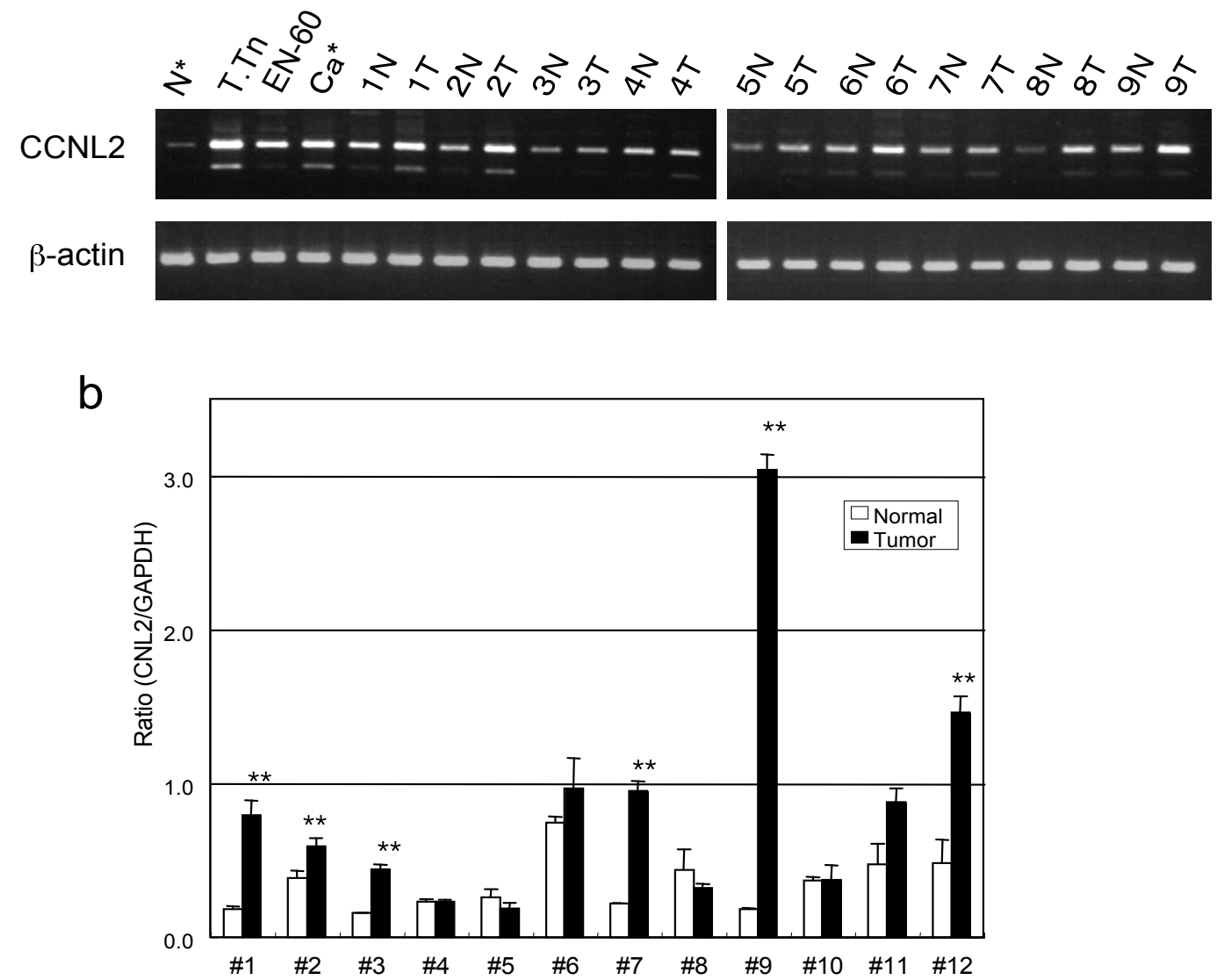

Figure 3: The expression of CCNL2 mRNA in normal and esophageal SCC tissues. a, The expression of CCNL2 (upper panel) and $\beta$-actin (lower panel) was examined by RT-PCR for specimens of normal $(\mathrm{N})$ and carcinoma (T) tissues resected from patients 1 to $9 . \mathrm{N}^{*}$ and $\mathrm{Ca}^{*}$ represent the products from RNA of normal esophageal keratinocytes and esophageal SCC, respectively, obtained from Cybrdi. T.Tn is a human esophageal SCC cell line, and EN-60 is an immortalized human esophageal keratinocyte. b. The expression of CCNL2 mRNA was examined by RT-qPCR in specimens of normal and esophageal SCC tissues resected from patients 1 to $12(\# 1$ - \#12). Each value was normalized with that of GAPDH, and the averages of three experiments are shown. The error bars represent $S D(n=3)$. Asterisks indicate a significant increase in carcinoma tissues as compared to normal tissues $\left({ }^{* *}, p<0.01\right.$, Student's test).

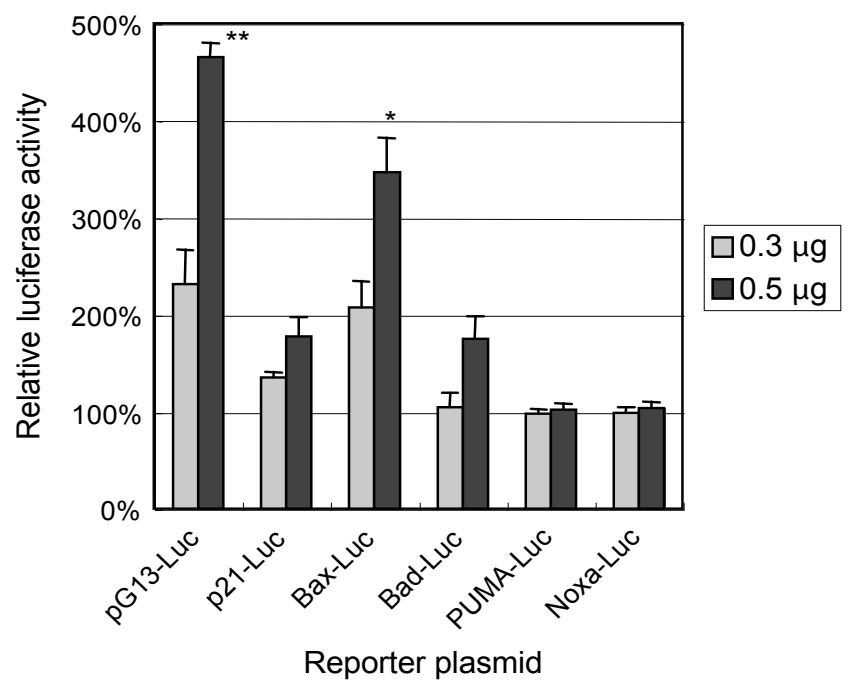

Figure 4: p53 reporter activation by CCNL2. ras-NIH3T3 cells were co-transfected with firefly reporter plasmids such as pG13-Luc, pGL3-p21-Luc, pGL3-Bax-Luc, pGL3-Bad-Luc, pBV-PUMA Frag2-Luc and pGV-B2 Noxa-Luc and a Renilla reporter plasmid, SV40-Rluc, together with a control empty vector or CCNL2 expression plasmid. Cells were harvested $48 \mathrm{~h}$ after transfection and luciferase activities in the cell extracts were measured. Activity of firefly luciferase was normalized by Renilla luciferase activity. The error bars represent $S D$. * $P<0.05$ and ${ }^{* *}, \mathrm{P}<0.01$ versus vector control, Student's $t$ test. 
Citation: Shimada H, Ito M, Kagaya A, Shiratori T, Kuboshima M, et al. (2015) Elevated Serum Antibody Levels against Cyclin L2 in Patients with Esophageal Squamous Cell Carcinoma. J Cancer Sci Ther 7: 060-066. doi:10.4172/1948-5956.1000326

and colon cancer compared with the those in healthy donors (Figure $2 b)$.

In our previous large-scale screening of esophageal SCC [5-11], we found that SEREX antigens may induce their serum antibodies through the overexpression of wild-types, expression of alternative splicing variants and/or altered protein processing. The development of s-CCNL2-Abs may be caused by the elevated expression of CCNL2 in esophageal SCC tissues, which does not occur in surrounding normal tissues (Figure 3). The possible involvement of promoter methylation in the regulation of CCNL2 expression level was also suggested [25].

CCNL2 was first identified as a RNA polymerase II-associated cyclin that induced the apoptosis of hepatocellular carcinoma cells
[26]. CCNL2-induced apoptosis in mouse embryonic carcinoma cells was also reported by Zhou et al. [27]. These results are consistent with our observation that induced expression of CCNL2 activated proapoptotic p53 (Figure 4). We also demonstrated that PKCa plays a crucial role in the upstream signaling pathway of p 53 activation by CCNL2 (Figure 5). PKCa plays an important role in the proliferation and malignant transformation [28,29]. Therefore, the activation of PKCa may be a main event caused by CCNL2, and activation of p53 might be a downstream branch pathways initiated by activated PKC $\alpha$.

Compared to ELISA, AlphaLISA is an excellent method for measuring antibody levels because it has low variations, stable background, and high specificity. It does not involve plate washing steps, but instead involves mixing of antigens with antibodies in sera
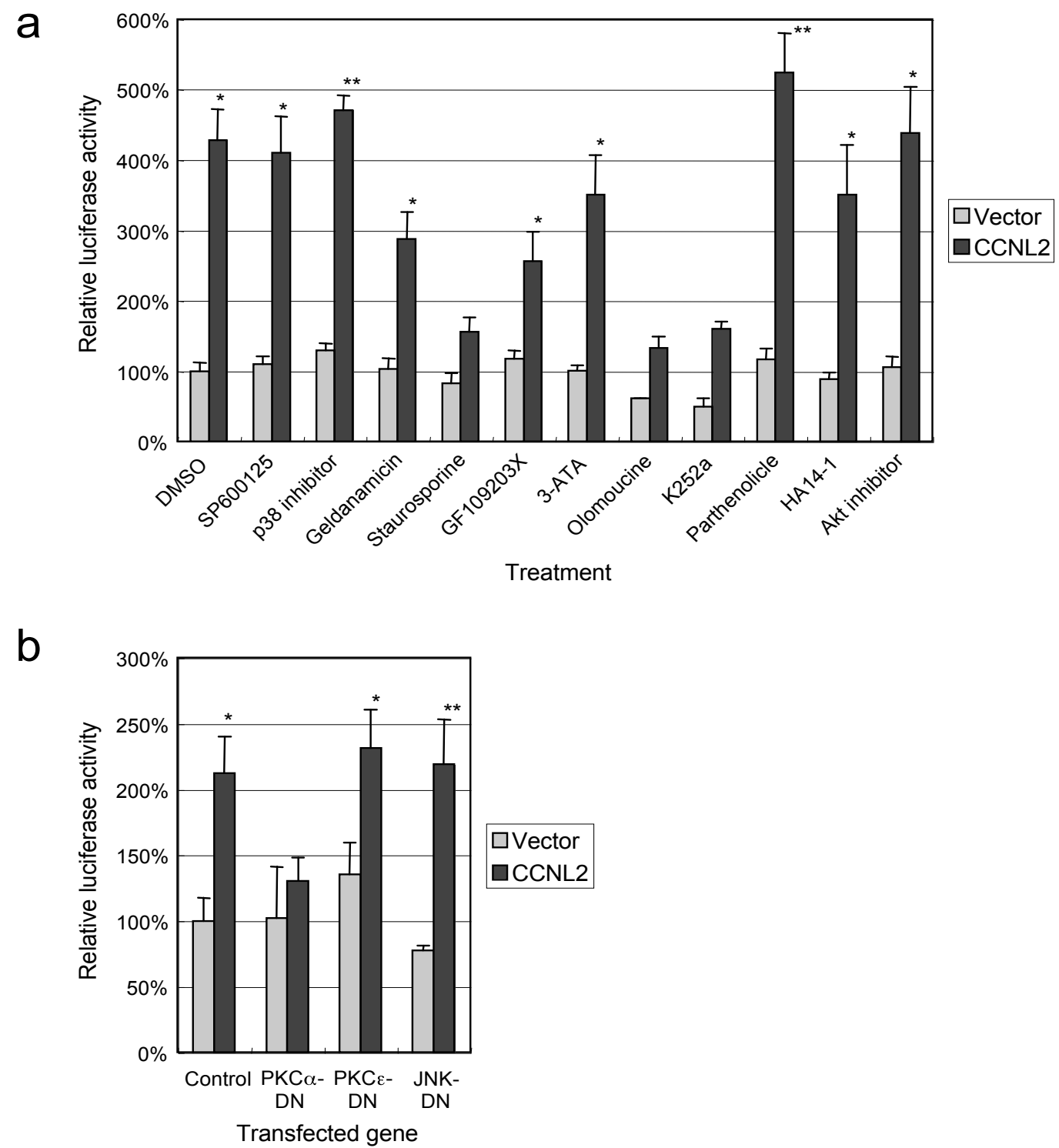

Figure 5: Suppression of CCNL2-induced p53 reporter activation by PKC inhibitors. a. ras-NIH3T3 cells were co-transfected with pG13-Luc, SV40-Rluc and CCNL2 expression plasmid or control plasmid, cultured for $24 \mathrm{~h}$, and then cultured in the presence of various inhibitors or control solvent DMSO (0.1\%) for another 24 $\mathrm{h}$. The final concentrations used were as follows: SP600125, $20 \mu \mathrm{M}$; p38 MAP kinase inhibitor, $2 \mu \mathrm{M}$; geldanamycin, $20 \mathrm{nM}$; staurosporine, $2.5 \mathrm{nM}$; GF109203X, $2 \mu \mathrm{g} /$ ml; 3-ATA, $5 \mu \mathrm{M}$; olomoucine, $50 \mu \mathrm{M}$; K252a, 500 nM; parthenolide, $1 \mu \mathrm{M}$; HA14-1, $10 \mu \mathrm{M}$; Akt inhibitor, $4 \mu \mathrm{M}$. b, ras-NIH3T3 cells were co-transfected with pG13-Luc, SV40-Rluc, expression plasmid of dominant negative PKCa (PKCa-DN), dominant negative PKCE (PKCE-DN), dominant negative JNK (JNK-DN) or control empty plasmid and CCNL2 expression plasmid or control plasmid. Cells were cultured for $48 \mathrm{~h}$ and then luciferase activity was measured. The error bars represent SD. ${ }^{*}, \mathrm{P}$ $<0.05$ and ${ }^{* *}, \mathrm{P}<0.01$ versus vector control, Student's t test. 
Citation: Shimada H, Ito M, Kagaya A, Shiratori T, Kuboshima M, et al. (2015) Elevated Serum Antibody Levels against Cyclin L2 in Patients with Esophageal Squamous Cell Carcinoma. J Cancer Sci Ther 7: 060-066. doi:10.4172/1948-5956.1000326

followed by the addition of donor and acceptor beads. For example, Figures $2 b$ and $2 c$ and Supplementary Tables S1 and S2 show highly reproducible results, including distributions, $\mathrm{P}$ values and positive rates, despite using different sets of sera from healthy donors and patients. The precise measurement offered by AlphaLISA may enable establishment of antibody markers, although most of the existing tumor diagnosis methods involve antigen markers, with the exception of the p53 marker [2,30]. Compared to the measurement of the antigen levels, measurement of antibodies is more sensitive because of the stability of IgG proteins and their amplification by repeated exposure of antigenic proteins. Before developing to a large size, small highlymalignant, tumors can induce tissue destruction, exposing normally intracellular proteins to antigen-presenting cells in plasma. Therefore, using antibody markers for diagnosis may enable tumor detection long before detection with antigen markers.

In summary, this study showed that $30 \%$ of esophageal SCC can be detected by examination of s-CCNL2-Abs. Because endoscopic examination is an expensive and painful procedure to be used in the routine screening of asymptomatic patients in high-risk groups, detection of s-CCNL2-Abs could serve as another useful and convenient blood test for detection of esophageal SCC. Because of the specificity of this serum marker to esophageal SCC, s-CCNL2-Abs should be a good candidate for combinatory blood tests to detect esophageal SCC.

\section{Acknowledgements}

This work was partly supported by a Grant for the 21st Century COE (Center of Excellence) Program, a Grant-in-Aid for Scientific Research from the Ministry of Education, Culture, Sports, Science and Technology of Japan and Goho Life Sciences International Fund.

We thank Drs. Bert Vogelstein (Howard Hughes Medical Institute), Mian Wu (University of Science and Technology of China), Nobuyuki Tanaka (Nippon Medical School), Shigeo Ohno (Yokohama City University School of Medicine) and Eisuke Nishida (Kyoto University) for providing reporter or expression plasmids.

\section{References}

1. Shimada H, Matsubara H, Okazumi S, Isono K, Ochiai T (2008) Improved surgical results in thoracic esophageal squamous cell carcinoma: a 40-year analysis of 792 patients. J Gastrointest Surg 12: 518-526

2. Shimada H, Takeda A, Arima M, Okazumi S, Matsubara H, et al. (2000) Serum p53 antibody is a useful tumor marker in superficial esophageal squamous cell carcinoma. Cancer 89: 1677-1683.

3. Sahin U, Türeci O, Schmitt H, Cochlovius B, Johannes T, et al. (1995) Human neoplasms elicit multiple specific immune responses in the autologous host. Proc Natl Acad Sci U S A 92: 11810-11813.

4. Cancer immunome database:http://www2.licr.org/CancerlmmunomeDB/

5. Nakashima K, Shimada H, Ochiai T, Kuboshima M, Kuroiwa N, et al. (2004) Serological identification of TROP2 by recombinant CDNA expression cloning using sera of patients with esophageal squamous cell carcinoma. Int $\mathrm{J}$ Cancer 112: 1029-1035.

6. Shimada H, Nakashima K, Ochiai T, Nabeya Y, Takiguchi M, et al. (2005) Serological identification of tumor antigens of esophageal squamous cell carcinoma. Int J Oncol 26: 77-86.

7. Kuboshima M, Shimada H, Liu TL, Nomura F, Takiguchi M, et al. (2006) Presence of serum tripartite motif-containing 21 antibodies in patients with esophageal squamous cell carcinoma. Cancer Sci 97: 380-386.

8. Hiwasa T, Shimada H, Kuboshima M, Shiratori T, Kagaya A, et al. (2009) Decrease in chemosensitivity against anticancer drugs by an esophageal squamous cell carcinoma SEREX antigen, AISEC. Int J Oncol 34: 641-648.

9. Hiwasa T, Shimada H, Ochiai T, Takiguchi M (2006) Serological identification of antigens by recombinant cDNA expression cloning (SEREX) using antibodies from patients with esophageal squamous cell carcinoma. In: Moleculomics and Thereafter (Hiwasa T, ed.). Kerala, India, Research Signpost, pp. 99-117.

10. Shimada H, Shiratori T, Yasuraoka M, Kagaya A, Kuboshima M, et al. (2009)
Identification of Makorin 1 as a novel SEREX antigen of esophageal squamous cell carcinoma. BMC Cancer 9: 232.

11. Kagaya A, Shimada $H$, Shiratori $T$, Kuboshima M, Nakashima-Fujita K, et al. (2011) Identification of a novel SEREX antigen family, ECSA, in esophageal squamous cell carcinoma. Proteome Sci 9: 31.

12. Baker SJ, Markowitz S, Fearon ER, Willson JK, Vogelstein B (1990) Suppression of human colorectal carcinoma cell growth by wild-type p53. Science 249: 912-915.

13. el-Deiry WS, Kern SE, Pietenpol JA, Kinzler KW, Vogelstein B (1992) Definition of a consensus binding site for p53. Nat Genet 1: 45-49.

14. Nakano K, Vousden KH (2001) PUMA, a novel proapoptotic gene, is induced by p53. Mol Cell 7: 683-694.

15. el-Deiry WS, Tokino T, Velculescu VE, Levy DB, Parsons R, et al. (1993) WAF a potential mediator of p53 tumor suppression. Cell 75: 817-825.

16. Miyashita T, Reed JC (1995) Tumor suppressor p53 is a direct transcriptional activator of the human bax gene. Cell 80: 293-299.

17. Jiang P, Du W, Heese K, Wu M (2006) The Bad guy cooperates with good cop p53: Bad is transcriptionally up-regulated by p53 and forms a Bad/p53 complex at the mitochondria to induce apoptosis. Mol Cell Biol 26: 9071-9082.

18. Oda E, Ohki R, Murasawa H, Nemoto J, Shibue T, et al. (2000) Noxa, a $\mathrm{BH} 3$-only member of the $\mathrm{Bcl}-2$ family and candidate mediator of p53-induced apoptosis. Science 288: 1053-1058.

19. Ohno S, Akira Y, Konno Y, Imajoh S, Suzuki K (1988) A novel phorbol este receptor/protein kinase, $\mathrm{nPKC}$, distantly related to the protein kinase $\mathrm{C}$ family. Cell 53: 731-741.

20. Takahashi K, Kanazawa H, Chan H, Hosono T, Takahara M, et al. (1990) A case of esophageal carcinoma metastatic to the mandible and characterization of two cell lines (T.T. and T.Tn.). Jpn J Oral Maxillofac Surg 36: 307-316.

21. Shimada H, Liu TL, Ochiai T, Shimizu T, Haupt Y, et al. (2002) Facilitation of adenoviral wild-type p53-induced apoptotic cell death by overexpression of p33 ING1 in T.Tn human esophageal carcinoma cells. Oncogene 21: 12081216.

22. Sekiya T, Fushimi M, Hori H, Hirohashi S, Nishimura S, et al. (1984) Molecular cloning and the total nucleotide sequence of the human c-Ha-ras-1 gene activated in a melanoma from a Japanese patient. Proc Natl Acad Sci U S A 81: 4771-4775.

23. Hiwasa T, Shimada H, Sakaida T, Kitagawa M, Kuroiwa N, et al. (2003) Drugsensitivity pattern analysis for study of functional relationship between gene products. FEBS Lett 552: 177-183.

24. Shinmen N, Koshida T, Kumazawa T, Sato K, Shimada H, et al. (2009) Activation of NFAT signal by p53-K120R mutant. FEBS Lett 583: 1916-1922.

25. Guo R, Wu G, Li H, Qian P, Han J, et al. (2013) Promoter methylation profiles between human lung adenocarcinoma multidrug resistant $A 549 /$ cisplatin (A549/DDP) cells and its progenitor A549 cells. Biol Pharm Bull 36: 1310-1316.

26. Yang L, Li N, Wang C, Yu Y, Yuan L, et al. (2004) Cyclin L, a novel RNA polymerase II-associated cyclin, is involved in pre-mRNA splicing and induces apoptosis of human hepatocellular carcinoma cells. J Biol Chem 279: 11639 11648.

27. Zhuo L, Gong J, Yang R, Sheng Y, Zhou L, et al. (2009) Inhibition of proliferation and differentiation and promotion of apoptosis by cyclin $\mathrm{L} 2$ in mouse embryonic carcinoma P19 cells. Biochem Biophys Res Commun 390: 451-457.

28. Nishizuka $Y$ (1984) The role of protein kinase $C$ in cell surface signal transduction and tumour promotion. Nature 308: 693-698.

29. Michie AM, Nakagawa R (2005) The link between PKCa regulation and cellular transformation. Immunol Lett 96: 155-162.

30. Shimada H, Yajima S, Oshima Y, Hiwasa T, Tagawa M, et al. (2012) Impact of serum biomarkers on esophageal squamous cell carcinoma. Esophagus 9 : $131-140$. 